\title{
APPLICATION OF TAGUCHI APPROACH IN THE OPTIMIZATION OF THE MECHANICAL PROPERTIES OF SNAIL-SHELL-FILLER/CHICKEN-FEATHER-FIBRE POLYMER BASED HYBRID COMPOSITE
}

\author{
Reuben Kabantiyok $^{1,2 *}$, Prof. DS Yawa ${ }^{2}$, Dr. MO Afolayan ${ }^{2}$ \\ ${ }^{1}$ Research and Development Centre, Defence Industries Corporation of Nigeria \\ ${ }^{2}$ Department of Mechanical Engineering, Ahmadu Bello University
}

\section{ARTICLE INFO}

Keywords:

SSPS; SSF; CFF;

Taguchi, ANOVA

\begin{abstract}
Many studies are on-going to optimize the properties of composites, this is because composite have found application in different industries due to their advantage of light weight. Scientists have turned their attention to using natural occurring materials for the development of novel materials. Animal waste is playing an important part in this area of application as using it is not only providing benign environmental solution but solving engineering challenges. In this study, the effect of three factors on the mechanical properties of the composite was studied. They are snail shell particulate size (SSPS), volume of snail shell filler (SSF) and chicken feather fibre (CFF) respectively. The composite were produced from four different SSPS $(75,150,300$ and $600 \mu \mathrm{m}), \%$ reinforcements of SSF $(2.5 \%, 5.0 \%, 7.5 \%$ and $10 \%)$ and CFF $(10 \%, 20 \%, 30 \%$ and $40 \%)$ respectively. The snail shell particulate and chicken feather fibre of varying \% composition were imbedded in the matrix of polyester resin. The experiments were conducted using Taguchi method L16 (4x3) with three design parameter SSPS, SSF and CFF at four level combinations. A total of sixteen runs of experiment were performed and the experimental data analysed using Taguchi optimization method with Minitab 18.1 software. ANOVA was used to statistically analyse and optimized the data and the significant influence of each parameter on the mechanical properties of the composite. Analysis were done at $95 \%$ confidence level and it was observed that CFF has $69.46 \%, 66.64 \%, 37.88 \%$ and $42.93 \%$ significant effect on UTS, Load, MOR and Impact strength respectively, while SSF and SPSS have $40.69 \%$ and $46.74 \%$ significant effect on MOE and Hardness value respectively. A verification test confirmed there were improvements in the $\mathrm{S} / \mathrm{N}$ ratios for all properties from the mean values to the experimental values except for Load.
\end{abstract}




\subsection{INTRODUCTION}

Natural fibres find application in diverse field of engineering applications. The ease at which wastes from animals and plants are been used as reinforcement either as fillers or fibres in composite development gives room for the development of new materials that has stood comparative advantages to metals and alloys. In simple definition, natural fibres are fibres that are not synthetic or manmade. They can be sourced from plants or animals (Ticoalu et al., 2010). Fibre reinforced polymer matrix got considerable attention in numerous applications because of the good properties and superior advantages of natural fibre over synthetic fibres in term of its relatively low weight, low cost, less damage to processing equipment, good relative mechanical properties such as tensile modulus and flexural modulus, improved surface finish of moulded parts composite, renewable resources, being abundant (Shalwan et al., 2013), ease of processing and less health hazard.

The utilization of natural fibres and fillers as reinforcement for composite materials based on thermoplastic and thermosetting polymers such as polypropylene and polyester is gaining ground in sustainable research area in the polymer world (Madueke et al., 2014). The fact that unsaturated polyester (UP) resins cures readily at room temperature makes it versatile when it comes to maintaining properties. Both thermoplastics and thermosets can reap the benefit of fibre reinforcement of which UP is an example of these thermosets. Researchers have taken to the use of hybrid composites by combining different types of fibres in a common matrix and this has proven to enhance the properties of natural fibre polymer reinforced composites.

Composite in simple terms can be defined as any material formed by combining the essential properties of individual elements in such a way that this combination produces enhance properties for the intended application. Usually, one component serves as continuous matrix and the other as fillers or reinforcements. The combination according to Kelly (1965) has its own distinctive properties, in terms of strength to resistance to heat or some other desirable quality, it is better than either of the components alone or radically different from either of them.

Today, the field of composite materials has attracted the attention of engineers and scientists all over the world. Composite materials have been applied to a variety of structural applications. Among the most reliable is the natural fibre composite, which possesses one of the highest specific moduli. The specific strength and stiffness of natural fibres composites are significantly greater than monolithic materials such as steel and aluminum, which make them attractive for numerous weight critical applications (Andreia et al., 2005). Over the years, researchers have engaged themselves to finding methods to improve impact properties of composites such as fibre and matrix toughening, interface toughening, through-the thickness reinforcements, and hybridizing (Bless et al., 2015).

Materials scientists and engineers all over the world has turned their attention towards the use of natural available resources to better the lives of people by developing new materials that are environmental friendly, have better properties so as to meet the needs of industries. Natural Fibre Polymer Reinforced Composites are partly replacing currently used glass or carbon fibre reinforced composites. They are high specific strength and modulus materials, low priced, recyclable and are readily available. They are a composite material consisting of a polymer matrix embedded with high-strength natural fibers, like jute, oil palm, sisal, kenaf, and flax (Ku et al., 2011). 


\subsection{SNAIL SHELL COMPOSITE (SSC)}

Snail Shell (SS) are waste products which are obtained from the consumption of a small brownish marine snail, which rests in a V shaped spiral shell, found in many coastal regions. These shells are a very strong, hard and brittle material. These snails are found in the lagoons and mudflats of the coastal areas, the people in this area consume the edible part as sea food and dispose the shell as a waste product, but a large amount of these shells are still disposed as waste and with disposal already constituting a problem in areas where they cannot find any use for it, and large deposits have accumulated in many places over the years (Syed et al., 2014).

The past decades have witnessed increasing interest in the use of fillers in the polymer industry. Snail Shell Filler (SSF) has been proven by different researchers (Madueke et al, 2014, Adunsaya et al., 2014, and Asafa, et al., 2015) to be reinforcing fillers as they have been recorded to have improved tensile, hardness and impact properties of polymeric composites. Fillers greatly enhance the dimensional stability, impact resistance, tensile and compressive strength, abrasion resistance and thermal stability when incorporated into polymers. Fillers which merely increase the bulk volume, and hence, reduce price, are known as extender fillers while those which improve the mechanical properties particularly tensile strength are termed as reinforcing fillers (Genevive et al., 2011).

In study on potentials of SSF as a reinforcement for discarded aluminum based materials, Asafa, et al., (2015) recorded that at $600 \mu \mathrm{m}$ particle size, the tensile strength increased from $92.4 \mathrm{MPa}$ at $0 \mathrm{wt} \%$ to $236 \mathrm{MPa}$ at $48 \mathrm{wt} \%$ with a corresponding increase hardness of 48.3 . The increase tensile strength is attributed to uniform distribution of SSF in the ductile aluminium matrix (Aigbodion and Hassan, 2007), while the hardness of the SSF is due to the presence of $\mathrm{CaCO}_{3}, \mathrm{C}$ and $\mathrm{SiO}_{2}$ of the chemical made up of the particles (Patricio et al., 2007).

In other related research Bienia et al., (2003) and Prasad et al., (2011) concluded that reinforcements enhanced tensile strength by matrix strengthening. This increment is attributed to an increase of the weight fraction of hard phase of the SSF. Therefore, researchers investigating the properties of SS particulate composite concluded it enhance properties for application in different areas with emphasis where impact properties is needed.

\subsection{CHICKEN FEATHER FIBRE (CFF)}

CFFs are composed of keratin proteins of 90wt\% (Lucas and Stettenheim, 1972). Approximately one quarter of the keratin protein is concentrated in the central portion of the molecule which is rich in hydrophobic residues (Odonnell and Suzuki, 1973). The high content of hydrophobic residues indicates that the fibres are compatible with organic liquids. A good compatibility with organic resins is essential for their applications in composite materials. CFFs have a high content of cysteine which connects to each other by disulfide bonds to form a cross-linked network. The highly cross-linked structure gives the feather good mechanical properties (Zhan and Wool, 2014). CFFs have been used in composites with different polymers, such as soy oil resins (Hong and Wool, 2005, Zhan and Wool, 2008), polypropylene (Barone and Schmidt, 2005) and epoxy resins (Zhan and Wool, 2010). CFFs have high resistivity and low dielectric constant; if combined with well-designed bio-based resins, the resulting composites are good for electrical insulator (Zhan et al., 2011, Zhan and Wool, 2010). More studies, however, are needed to investigate the properties of CFFs, which is beneficial for further study of its applications in composite materials.

Investigation into the mechanical properties of CFFs shows that it tensile modulus is within the range of $3.59 \pm 1.09 \mathrm{GPa}$ (Zhan and Wool, 2011). This range was further buttressed in a related study on the investigation of mechanical properties in polyester and phenylester composites reinforced with CFF (Subramani et al., 2014) where a tensile $\left(4.719 \mathrm{~N} / \mathrm{mm}^{2}\right.$ ), flexural 
$(15.821 \mathrm{MPa})$ and impact $(0.4 \mathrm{~J})$ properties of the composite at $20 \% \mathrm{CFF}$ and $80 \%$ Polyester was recorded.

Though SSF and CFF has been used individually or in combination with other reinforcements in polymer based composite, to the best of my knowledge the combined effect of SSF and CFF as reinforcement in polyester matrix composite has never been investigated. Presented here is a study of a SSF/CFF Polyester Based Composite. The used of Taguchi method was employed to evaluate the mechanical properties of SSF/CFF reinforced polyester composite. The effect of the combination of individual constituent elements; filler (SSF) and fibre (CFF) as well as the variation of particle size of the filler, weight percent and their effects on the mechanical properties of the composite is worth studying. It will be needful for researches to not only base their research on experimental test but also on verifiable optimized conditions. To obtain the significant factors affecting responses, ANOVA is carried out and a confirmatory test done to validate the study.

\subsection{MATERIALS AND METHODS}

The following materials were used for the experiment: Snail Shell Particulate, Chicken Feather Fibre, Polyester Resin, Cobalt Accelerator, Methyl-Ethyl ketone Catalyst, Laundry Detergent, Sodium Chloride and Ethanol $\left(\mathrm{C}_{2} \mathrm{H}_{5} \mathrm{OH}\right)$

\subsection{SNAIL SHELL FILLER (SSF)}

The Snail shell was obtained from Kaduna Central Market, Nigeria. It was washed with the warm water mixed with laundry detergent and properly rinsed, oven dried to remove water and milled to particle sizes of 75, 150, 300 and 600 microns.

\subsection{CHICKEN FEATHER FIBRE (CFF)}

The chicken feathers were obtained from poultry processing site in Samaru Market, Zaria, Nigeria. It washed several times with water mixed with laundry detergent, sodium chloride and ethanol to remove blood stains, manure, extraneous materials, sanitised and odour free feathers. The clean feathers were dried in a vacuum oven at $60^{\circ} \mathrm{C}$ for $10-12$ hours and fibres (barbs) were manually and carefully cut off the quill with a scissor.

\subsection{TAGUCHI METHOD OF EXPERIMENTAL DESIGN AND ANALYSIS}

In the past, researchers are saddle with the rigorous methods of carrying out very large number of experiments to arrive at a result. This is very tedious, tiring and very expensive. For example, if this study were to be done using the traditional experimental design, 64 runs of experiments are to be performed but with Taguchi, this was reduced to 16 .

This is a huge relief. Taguchi methods have been widely utilized in engineering analysis and consist of a plan of experiments with the objective of acquiring data in a controlled way in order to obtain information about the behaviour of a given process (Kuram et al., 2010, Kolahan et al., 2011, Chomsamutr and Jongprasithporn., 2012 and Rama and Padmanabhan., 2012, Motorcu., 2016, ). Taguchi translate responses into statistical measure called signal to noise ratio (S/N ratio). Signal being the property of interest and the noise being unwanted property. Three conditions are spelt out for these ratios, Larger is Better, Smaller is Better and Nominal is Better. In this study, "Larger is Better" condition is used corresponding to equation (1).

$$
\mathbf{S} / \mathbf{N}=-10 * \log \left(\sum\left(1 / \mathbf{y}^{2}\right) / \mathbf{n}\right)
$$


Where $\mathrm{y}=$ responses for the given factor level combination and $\mathrm{n}=$ number of responses in the factor level combination.

This means the $\mathrm{S} / \mathrm{N}$ ratio for the maximum load, ultimate tensile strength, flexural strength, impact strength and hardness properties are the values of interest.

Taguchi $\mathrm{L}_{16}(4 \times 3)$ orthogonal array was used. The representation is shown in table 1.16 experiments, 3 columns and 16 rows to treat 3 parameters with four levels, each representing variable factors as tabulated in table 2. Minitab 18.1 software was used to transform the responses to signal to noise ratio, compared interactions and also for the computation of ANOVA.

Design Summary of the experiment

Taguchi Array

Factors:

Runs:
$\mathrm{L} 16\left(4^{\wedge} 3\right)$

3

16

Table 1: Showing parameters, code and levels

\begin{tabular}{|l|c|c|c|c|c|}
\hline \multirow{2}{*}{ Parameter } & \multirow{2}{*}{ Code } & \multicolumn{4}{|c|}{ Levels } \\
\cline { 3 - 6 } & & 1 & 2 & 3 & 4 \\
\hline SSPS $(\mu \mathrm{m})$ & A & 75 & 150 & 300 & 600 \\
\hline SSF (wt.\%) & B & 2.5 & 5 & 7.5 & 10 \\
\hline CFF (wt.\%) & C & 10 & 20 & 30 & 40 \\
\hline
\end{tabular}

Table 2: Experimental Runs

\begin{tabular}{cccc}
\hline NoE & A & B & C \\
\hline 1 & 1 & 1 & 1 \\
2 & 1 & 2 & 2 \\
3 & 1 & 3 & 3 \\
4 & 1 & 4 & 4 \\
5 & 2 & 1 & 2 \\
6 & 2 & 2 & 1 \\
7 & 2 & 3 & 4 \\
8 & 2 & 4 & 3 \\
9 & 3 & 1 & 3 \\
10 & 3 & 2 & 4 \\
11 & 3 & 3 & 1 \\
12 & 3 & 4 & 2 \\
13 & 4 & 1 & 4 \\
14 & 4 & 2 & 3 \\
15 & 4 & 3 & 2 \\
16 & 4 & 4 & 1
\end{tabular}


A total of 16 experimental runs were conducted with different particle sizes of A (SSPS) and different wt\% of B (SSF) in combination with different wt\% of $\mathrm{C}(\mathrm{CFF})$ were impregnated in a matrix of polyester resin.

\subsection{PREPARATION OF THE COMPOSITE}

The composites were prepared using the hand laying methods by reinforcing a known percentage weight of SSF (2.5, 5.0, 7.5 and 10wt\% respectively) and CFF (10, 20, 30 and 40wt\% respectively) in polyester resin. The mixture was thoroughly stirred to ensure uniform distribution of constituents and gradually poured into a mould of size $150 \mathrm{~mm} \times 150 \mathrm{~mm} \times 7 \mathrm{~mm}$. the mixture was done at $80^{\circ} \mathrm{C}$ with a pressure of $25 \mathrm{bar}$ for 10 minutes and allowed to cure at room temperature for 24 hours. This procedure was repeated for other specimen as shown in table 2 with changes in the weight percentages of the constituents and corresponding results recorded as shown in table 3 . A control sample was produced without the addition of the reinforcements SSF and SFF. After curing, the samples were removed from the mould and the mechanical test done.

\subsection{MECHANICAL TEST}

Tensile Test: Monsanto Tensometer type 'w' S/no 9875 was used for the tensile testing of the samples. The tensile test specimen preparation and testing procedures were conducted in accordance with the American Society of Testing and Materials D412 (ASTM D412)

Flexural Test: Three points flexural testing was conducted using a Universal Materials Testing machine Cat. Nr. 261. The flexural test was carried according to ASTM D7264

Hardness Test: The hardness test for all the samples were carried using Vicker Hardness Tester Model MV1-PC S/n 07/2012-1329.

Impact Test: The impact test was carried out using Charpy Impact Machine Cat. Nr. 412 having a capacity of $15 \mathrm{~J}$ and $25 \mathrm{~J}$.

\subsection{RESULTS AND DISCUSSION \\ 3.1 RESULTS}

Table 3, 4 and 5 and Fig.1 and 2 shows the experimental results, SN Ratios, Response Table, graphs and effect of parameters Ultimate Tensile Strength (UTS), Load (L), Modulus of Elasticity (MOE), Modulus of Rupture (MOR), Impact Strength (IMP) and Hardness Value (HV) respectively.

Table 3: Experimental results for UTS, Load, MOE, MOR, IMP and HV

\begin{tabular}{|c|c|c|c|c|c|c|c|c|c|}
\hline NoE & A & B & $\mathbf{C}$ & $\begin{array}{c}\text { UTS } \\
\text { (MPa) }\end{array}$ & $\begin{array}{l}\text { LOAD } \\
\text { (MPa) }\end{array}$ & $\begin{array}{l}\text { MOE } \\
(\text { MPa) }\end{array}$ & $\begin{array}{l}\text { MOR } \\
(\mathrm{MPa})\end{array}$ & $\begin{array}{c}\text { IMP } \\
(\mathbf{J})\end{array}$ & HV \\
\hline
\end{tabular}




$\begin{array}{cccccccccc}1 & 1 & 1 & 1 & 17.83 & 1083.33 & 849.32 & 14.49 & 0.6 & 5.6 \\ 2 & 1 & 2 & 2 & 5.46 & 380 & 134.46 & 7.05 & 2.45 & 5.2 \\ 3 & 1 & 3 & 3 & 7.04 & 416.67 & 618.22 & 12.99 & 7.33 & 5.77 \\ 4 & 1 & 4 & 4 & 3.74 & 225 & 40.39 & 1.41 & 1.25 & 4.53 \\ 5 & 2 & 1 & 2 & 9.74 & 650 & 651.89 & 20.97 & 5.18 & 3.6 \\ 6 & 2 & 2 & 1 & 15.57 & 1050 & 693 & 11.4 & 4.18 & 11.33 \\ 7 & 2 & 3 & 4 & 4.36 & 300 & 310.08 & 9.78 & 4.8 & 5.97 \\ 8 & 2 & 4 & 3 & 9.35 & 641.67 & 519.57 & 12.68 & 6.22 & 8.07 \\ 9 & 3 & 1 & 3 & 4.26 & 300 & 347.77 & 13.69 & 5.88 & 3.9 \\ 10 & 3 & 2 & 4 & 4.39 & 325 & 29.19 & 1.9 & 2.02 & 6.43 \\ 11 & 3 & 3 & 1 & 12.28 & 783.33 & 1055.55 & 22.44 & 3.07 & 14.3 \\ 12 & 3 & 4 & 2 & 3.59 & 241.67 & 762.73 & 23.52 & 0.42 & 15.07 \\ 13 & 4 & 1 & 4 & 11.87 & 700 & 809.35 & 20.72 & 6.7 & 8.63 \\ 14 & 4 & 2 & 3 & 10.68 & 766.67 & 588.88 & 17.82 & 5.43 & 10.33 \\ 15 & 4 & 3 & 2 & 8.94 & 625 & 1523.93 & 22.82 & 5.43 & 11.23 \\ 16 & 4 & 4 & 1 & 13.05 & 766.67 & 398.01 & 6.14 & 4 & 6.5\end{array}$

\subsection{DISCUSSION}

The UTS, Load, MOE, MOR, Impact Strength and Hardness values of the composite is measured at different levels of the reinforcements of chicken feather fibre (CFF), snail shell filler (SSF) and the snail shell particle size (SSPS) as shown in Table 1. The variation of the properties measured as reinforcements and particle sizes are increase are shown in Fig.1.

From Fig. 1 (a), it can be seen that as reinforcement and particle size increases from $1-2$, there is a decrease in the ultimate tensile strength (UTS), from $14.683 \mathrm{MPa}$ being the maximum value recorded when $10 \mathrm{wt} \% \mathrm{CFF}$ was used to $6.09 \mathrm{MPa}$ when $40 \mathrm{wt} \% \mathrm{CFF}$ was used. The decrease in strength is possibly because of the inability of the resin to hold the reinforcements together. The maximum and minimum Load the composite can carry are recorded in Fig.1 (b). 920.8MPa at $10 \mathrm{wt} \% \mathrm{CFF}$ and $387.5 \mathrm{MPa}$ at $40 \mathrm{wt} \% \mathrm{CFF}$. The same trend with UTS is observed with Load. The increase in the reinforcements decreases the load carrying capacity of the composite, this is so because the matrix volume decrease as the $\%$ reinforcement increases which will mean a reduction in the binding force. A slight deviation is noticed with MOE, Fig.1 (c). MOE decreases as the $\mathrm{wt} \% \mathrm{CFF}$ increases and increases as the particle size increases but fluctuates as $\mathrm{wt} \% \mathrm{SSF}$ increases. A maximum value of $876.9 \mathrm{MPa}$ is observed at $7.5 \mathrm{wt} \% \mathrm{SSF}$, while the minimum value of 297.3MPa is observed at $40 \mathrm{wt} \% \mathrm{CFF}$.

Fig.1 (d) shows a maximum value of $18.59 \mathrm{MPa}$ at $20 \mathrm{wt} \% \mathrm{CFF}$ and a minimum value of $7.89 \mathrm{MPa}$ at 600 microns. MOR increased suddenly from $10 \mathrm{wt} \% \mathrm{CFF}$ to $20 \mathrm{wt} \% \mathrm{CFF}$ and drops steadily, while a steady rise is observed as particle size increases from $75 \mathrm{microns}$ to $600 \mathrm{microns}$. The increase in MOR is as a result of larger surface area of interaction of the molecules of the snail shell, while the decrease must have been as a result of too much fibre competing for the resin. Finally, for impact strength and hardness, the maximum values are $6.215 \mathrm{~J}$ and $9.925 \mathrm{HV}$ at $30 \mathrm{wt} \% \mathrm{CFF}$ and 300 microns respectively, while the minimum values are $2.848 \mathrm{~J}$ and $5.275 \mathrm{HV}$ at 300 and 75 microns respectively. A rise in impact strength is observed as CFF increases from 10wt\% to 30wt\% then drops. As both SSF and SSPS increases, the Hardness value increases but a contrary effect is noticed with CFF. Summarily, Table 4 ranked which parameter has the main controlling effect on the UTS, Load, MOE, MOR, Impact Strength and Hardness. For UTS, Load, MOE, and MOR it is CFF, while for Impact Strength and Hardness it is SSPS. 


\subsection{SIGNAL TO NOISE RATIO (SNRA)}

Signal to noise ratio (SNRA) represents the degree of influence of each parameter (A, B and C) on the UTS, Load, MOE, MOR, Impact Strength and Hardness value of the composite at different level of interaction are shown in Table 4. The main effects of the parameters corresponding to 'larger is better' are the values corresponding to the peak of the graphs in Fig. 2 (a) - (f). The maximum response from each parameter in Table 5 (a) - (f) are highlighted in bold. This means that the optimum combination of the parameters for better properties are: A4B1C1 for UTS, A4B1C1 for Load, A4B3C1 for MOE, A4B1C2 for MOR, A4B3C3 for Impact and A4B3C1 for Hardness. Table 5 shows the maximum values (in bold) of UTS, Load, MOE, MOR, Impact Strengths and Hardness obtained as a result of the influence of parameter A, B and C. It is on these bases that the optimum combination is selected.

Fig.1. Graphs of UTS, Load, MOE, MOR, Impact Strength and Hardness versus CFF, SFF and SSPS

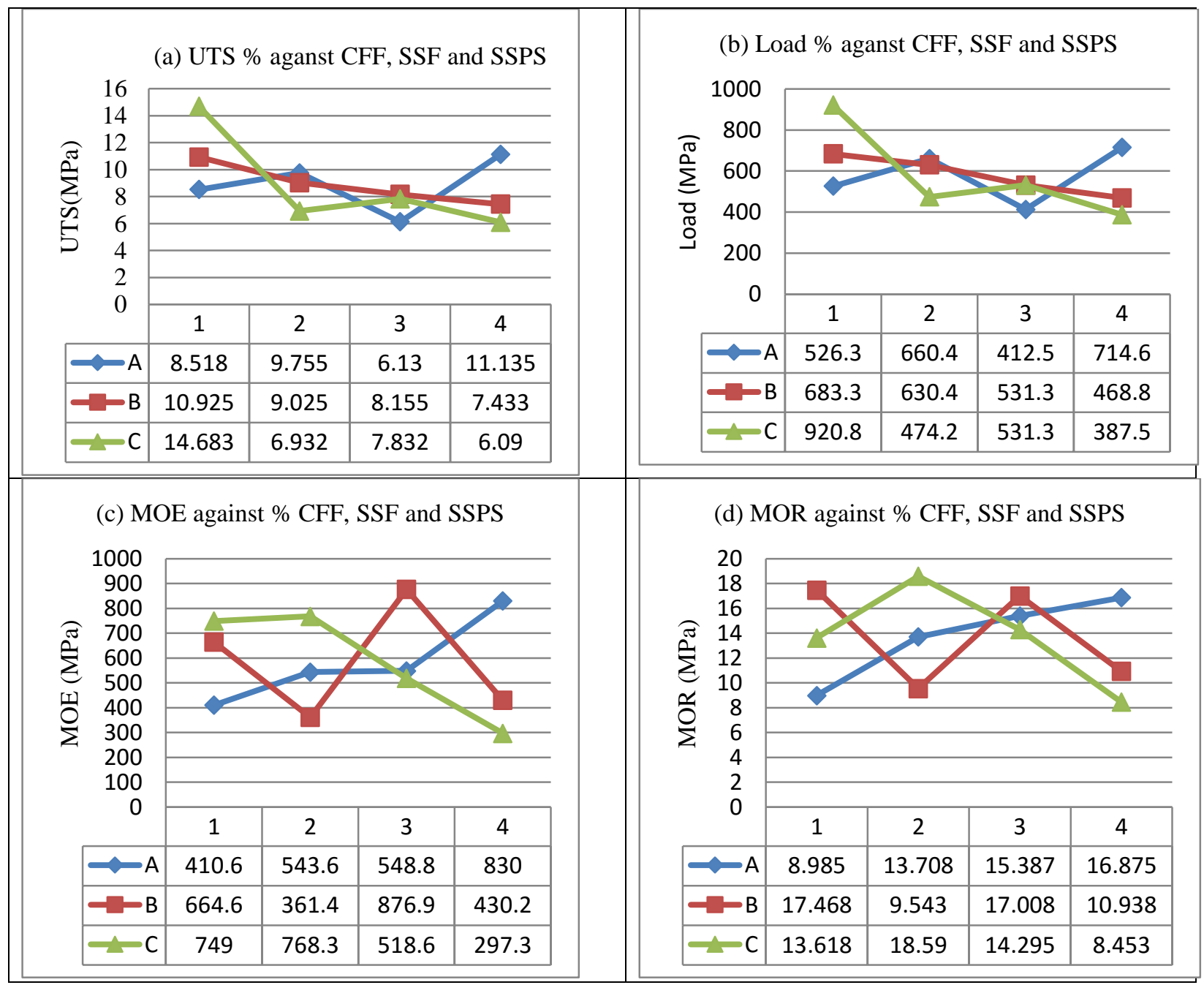




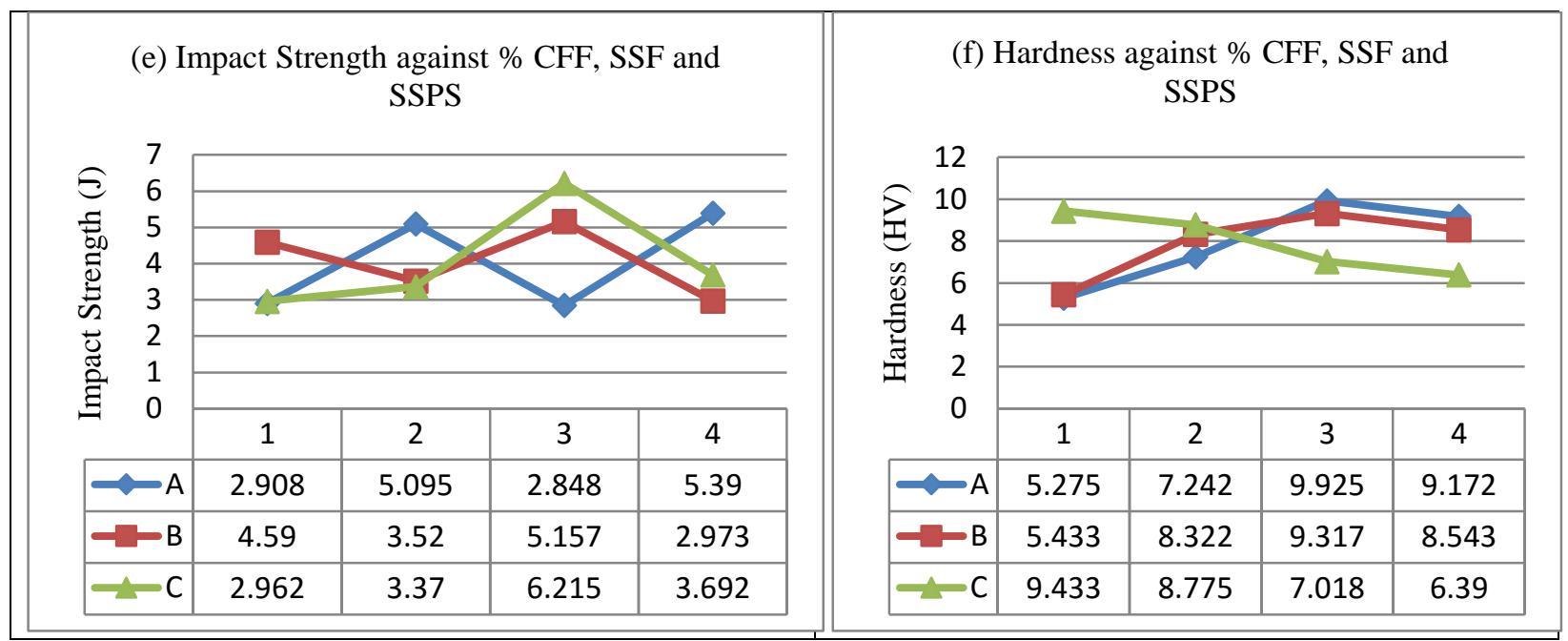

Table 4: SN Ratio for UTS, Load, MOE, MOR, Impact Strength and HV

\begin{tabular}{rrrrcccccc}
\hline NoE & A & B & C & $\begin{array}{c}\text { SNRA } \\
\text { UTS }\end{array}$ & $\begin{array}{c}\text { SNRA } \\
\text { LOAD }\end{array}$ & $\begin{array}{c}\text { SNRA } \\
\text { MOE }\end{array}$ & $\begin{array}{c}\text { SNRA } \\
\text { MOR }\end{array}$ & $\begin{array}{c}\text { SNRA } \\
\text { IMPACT }\end{array}$ & $\begin{array}{c}\text { SNRA } \\
\text { HARDNESS }\end{array}$ \\
\hline 1 & 1 & 1 & 1 & 25.023 & 60.7 & 58.58 & 23.22 & -4.44 & 14.96 \\
2 & 1 & 2 & 2 & 14.744 & 51.6 & 42.57 & 16.96 & 7.78 & 14.32 \\
3 & 1 & 3 & 3 & 16.951 & 52.4 & 55.82 & 22.27 & 17.30 & 15.22 \\
4 & 1 & 4 & 4 & 11.457 & 47.04 & 32.13 & 2.98 & 1.94 & 13.12 \\
5 & 2 & 1 & 2 & 19.771 & 56.26 & 56.28 & 26.43 & 14.29 & 11.13 \\
6 & 2 & 2 & 1 & 23.846 & 60.42 & 56.81 & 21.14 & 12.42 & 21.08 \\
7 & 2 & 3 & 4 & 12.790 & 49.54 & 49.83 & 19.81 & 13.62 & 15.52 \\
8 & 2 & 4 & 3 & 19.416 & 56.15 & 54.31 & 22.06 & 15.88 & 18.14 \\
9 & 3 & 1 & 3 & 12.588 & 49.54 & 50.83 & 22.73 & 15.39 & 11.82 \\
10 & 3 & 2 & 4 & 12.849 & 50.24 & 29.30 & 5.58 & 6.11 & 16.16
\end{tabular}




$\begin{array}{llllllllll}11 & 3 & 3 & 1 & 21.784 & 57.88 & 60.47 & 27.02 & 9.74 & 23.11 \\ 12 & 3 & 4 & 2 & 11.102 & 47.66 & 57.65 & 27.43 & -7.54 & 23.56 \\ 13 & 4 & 1 & 4 & 21.489 & 56.9 & 58.16 & 26.33 & 16.52 & 18.72 \\ 14 & 4 & 2 & 3 & 20.571 & 57.69 & 55.40 & 25.02 & 14.70 & 20.28 \\ 15 & 4 & 3 & 2 & 19.027 & 55.92 & 63.66 & 27.17 & 14.70 & 21.01 \\ 16 & 4 & 4 & 1 & 22.312 & 57.69 & 52.00 & 15.76 & 12.04 & 16.26\end{array}$

Table 5: Response Table for SNRA
(a) UTS
(b) Load

\begin{tabular}{|c|c|c|c|c|c|c|c|}
\hline Level & $\mathrm{A}$ & $\mathrm{B}$ & $\mathrm{C}$ & Level & $\mathrm{A}$ & $\mathrm{B}$ & $\mathrm{C}$ \\
\hline 1 & 17.04 & 19.72 & 23.24 & 1 & 52.93 & 55.85 & 59.17 \\
\hline 2 & 18.96 & 18.00 & 16.16 & 2 & 55.59 & 54.99 & 52.86 \\
\hline 3 & 14.58 & 17.64 & 17.38 & 3 & 51.33 & 53.93 & 53.94 \\
\hline 4 & 20.85 & 16.07 & 14.65 & 4 & 57.05 & 52.14 & 50.93 \\
\hline Delta & 6.27 & 3.65 & 8.59 & Delta & 5.72 & 3.71 & 8.24 \\
\hline Rank & 2 & 3 & 1 & Rank & 2 & 3 & 1 \\
\hline \multicolumn{4}{|c|}{ (c) MOE } & \multicolumn{4}{|c|}{ (d) MOR } \\
\hline Level & A & $\mathrm{B}$ & $\mathrm{C}$ & Level & $\mathrm{A}$ & $\mathrm{B}$ & $\mathrm{C}$ \\
\hline 1 & 47.28 & 55.96 & 56.97 & 1 & 16.36 & 24.68 & 21.79 \\
\hline 2 & 54.31 & 46.02 & 55.04 & 2 & 22.36 & 17.17 & 24.50 \\
\hline 3 & 49.56 & 57.45 & 54.09 & 3 & 20.69 & 24.07 & 23.02 \\
\hline 4 & 57.31 & 49.02 & 42.36 & 4 & 23.57 & 17.06 & 13.67 \\
\hline Delta & 10.03 & 11.42 & 14.61 & Delta & 7.21 & 7.62 & 10.82 \\
\hline Rank & 3 & 2 & 1 & Rank & 3 & 2 & 1 \\
\hline
\end{tabular}

(e) IMPACT

(f) HARDNESS

\begin{tabular}{|c|c|c|c|c|c|c|c|}
\hline Level & A & $\mathrm{B}$ & $\mathrm{C}$ & Level & A & $\mathrm{B}$ & $\mathrm{C}$ \\
\hline 1 & 5.647 & 10.440 & 7.443 & 1 & 14.41 & 14.16 & 18.85 \\
\hline 2 & 14.053 & 10.252 & 7.308 & 2 & 16.47 & 17.96 & 17.50 \\
\hline 3 & 5.926 & 13.841 & 15.815 & 3 & 18.66 & 18.71 & 16.37 \\
\hline 4 & 14.489 & 5.580 & 9.548 & 4 & 19.07 & 17.77 & 15.88 \\
\hline Delta & 8.842 & 8.261 & 8.508 & Delta & 4.66 & 4.56 & 2.97 \\
\hline Rank & 1 & 3 & 2 & Rank & 1 & 2 & 3 \\
\hline
\end{tabular}

The degree which parameters A, B and C affect the mechanical properties of the composite are gotten from the main effect, Delta (Table 5) of A, B and C. Delta is simply the difference between the highest and lowest value among the levels. 
Fig. 2: Effect of parameter on UTS, Load, MOE, MOR, Impact Strength and Hardness Values

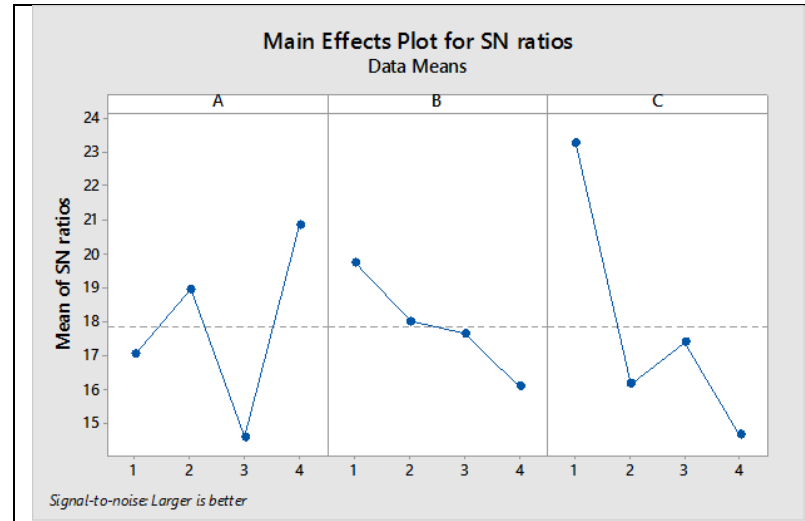

(a) SNRA_UTS ratio

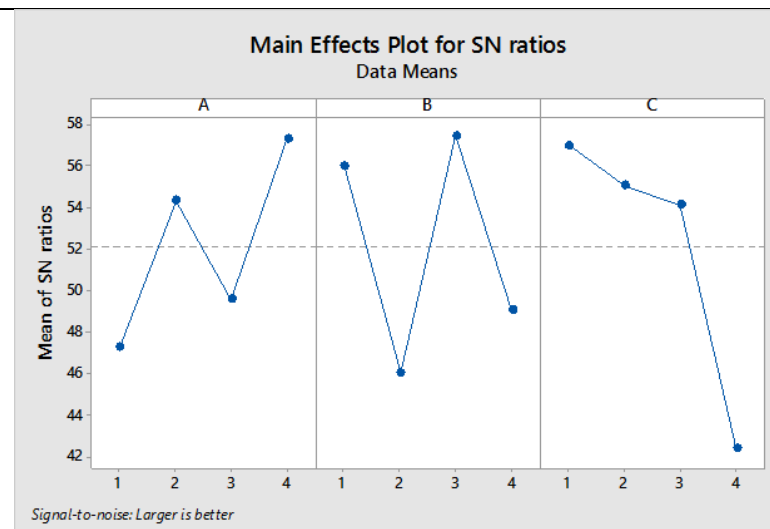

(c) SNRA_MOE ratio

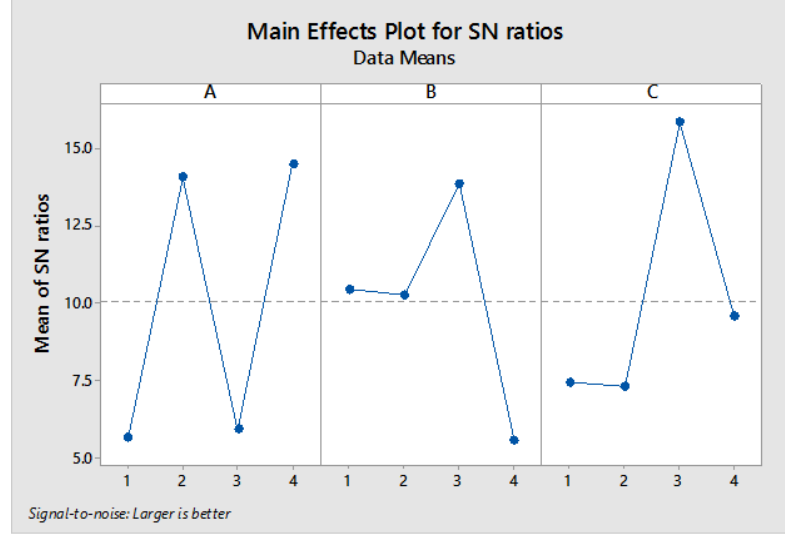

(e) SNRA_Impact ratio

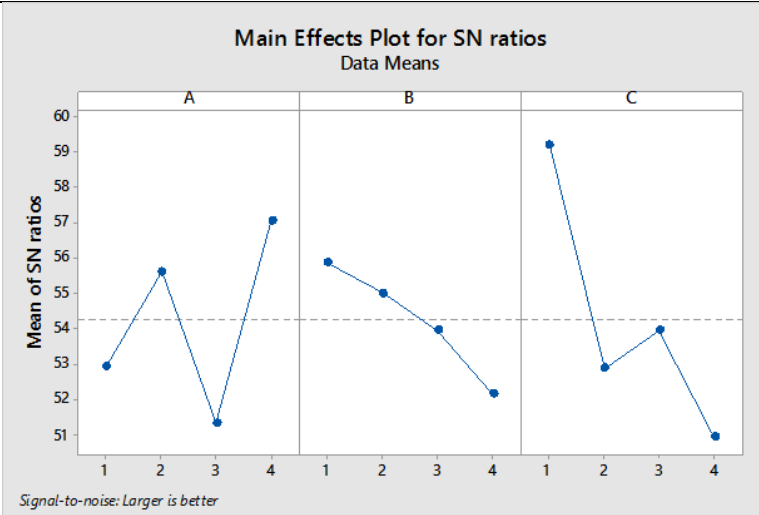

(b) SNRA_Load ratio

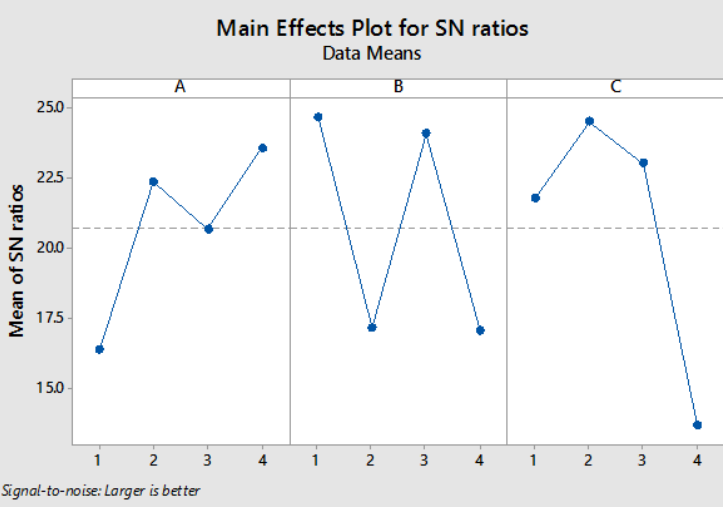

(d) SNRA_MOR ratio

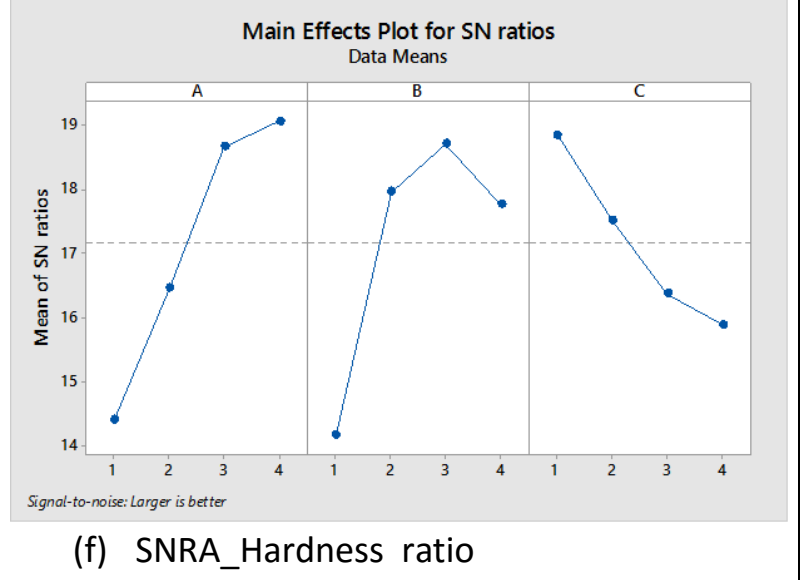

The formulation for optimal design for the best mechanical properties for these study which corresponds to 'Larger is Better' is taken from the graphs in Fig.2

According to Taguchi, larger SNRA values correspond to better design. Therefore, prediction of optimum design for the best mechanical properties in this study correspond to A4B1C1 for UTS Fig. 2(a), A4B1C1 for Load Fig. 2(b), A4B3C1 for MOE Fig. 2(c), A4B1C3 for MOR Fig. 2(d), A4B3C3 for Impact strength Fig. 1(e) and A4B3C1 for Hardness value Fig 1(f) respectively. 


\subsection{ANALYSIS OF VARIANCE (ANOVA)}

Analysis of variance (ANOVA) is a statistical tool used by researchers to know to what extent factors influence the outcome of experiments and interaction, confidence interval and test of significance (Montgomery, 2001). Table 5 shows the P-values for UTS, Load, MOE, MOR, Impact strength and Hardness values and their influences. The P-value of 0.006 (CFF) for UTS, 0.01 (CFF) for Load, 0.1999 (SSF) for MOE, 0.262 (CFF) for MOR, 0.059 (CFF) for impact strength and 0.360 (SPSS) for hardness values respectively have significant influence on these properties. This means CFF has $69.46 \%, 66.64 \%, 37.88 \%$ and $42.93 \%$ significant effect on UTS, Load, MOR and Impact respectively, while SSF and SPSS have $40.69 \%$ and $46.74 \%$ significant effect on MOE and Hardness value respectively. With these, depending on properties of interest one will watch the variation of CFF closely if UTS, Load, MOR and Impact strength are the properties of interest, SSF if MOE is the properties of interest and SPSS if Hardness is the properties of interest.

Table 5: ANOVA Table for UTS, Load, MOE, MOR, Impact and Hardness

\begin{tabular}{|c|c|c|c|c|c|}
\hline $\begin{array}{r}\text { (a) } \\
\text { Source }\end{array}$ & UTS & Adj SS & Adj MS & $\begin{array}{r}\text { F- } \\
\text { Value }\end{array}$ & $\begin{array}{r}\text { P- } \\
\text { Value }\end{array}$ \\
\hline $\bar{A}$ & 3 & 54.18 & 18.059 & 3.44 & 0.093 \\
\hline B & 3 & 27.3 & 9.098 & 1.73 & 0.26 \\
\hline $\mathrm{C}$ & 3 & 185.37 & 61.791 & 11.76 & 0.006 \\
\hline Error & 6 & 31.53 & 5.254 & & \\
\hline Total & 15 & 298.37 & & & \\
\hline
\end{tabular}

\begin{tabular}{crrrrr} 
(b) & Load & & & F- & $\begin{array}{r}\text { P- } \\
\text { Source }\end{array}$ \\
DF & Adj SS & Adj MS & Value & Value \\
\hline A & 3 & 222060 & 74020 & 3.21 & 0.104 \\
B & 3 & 111852 & 37284 & 1.62 & 0.282 \\
C & 3 & 667164 & 222388 & 9.65 & 0.01 \\
Error & 6 & 138287 & 23048 & & \\
\hline Total & 15 & 1139364 & & & \\
\hline
\end{tabular}

(c) MOE

\begin{tabular}{crrrrr} 
Source & DF & Adj SS & Adj MS & $\begin{array}{r}\text { F- } \\
\text { Value }\end{array}$ & $\begin{array}{r}\text { P- } \\
\text { Value }\end{array}$ \\
\hline A & 3 & 373884 & 124628 & 1.2 & 0.388 \\
B & 3 & 662115 & 220705 & 2.12 & 0.199 \\
C & 3 & 590648 & 196883 & 1.89 & 0.232 \\
Error & 6 & 624972 & 104162 & & \\
\hline Total & 15 & 2251618 & & & \\
\hline
\end{tabular}

(e) IMPACT

\begin{tabular}{|c|c|c|c|c|c|}
\hline Source & DF & Adj SS & Adj MS & $\begin{array}{r}\text { F- } \\
\text { Value }\end{array}$ & $\begin{array}{r}\text { P- } \\
\text { Value }\end{array}$ \\
\hline $\mathrm{A}$ & 3 & 22.55 & 7.518 & 3.81 & 0.077 \\
\hline B & 3 & 11.84 & 3.946 & 2 & 0.215 \\
\hline $\mathrm{C}$ & 3 & 25.84 & 8.613 & 4.37 & 0.059 \\
\hline Error & 6 & 11.83 & 1.972 & & \\
\hline Total & 15 & 72.07 & & & \\
\hline
\end{tabular}

(d) MOR

\begin{tabular}{crrrrr} 
Source & DF & Adj SS & Adj MS & $\begin{array}{r}\text { F- } \\
\text { Value }\end{array}$ & $\begin{array}{r}\text { P- } \\
\text { Value }\end{array}$ \\
\hline A & 3 & 140.6 & 46.87 & 1.16 & 0.398 \\
B & 3 & 200.2 & 66.73 & 1.66 & 0.274 \\
C & 3 & 207.2 & 69.07 & 1.72 & 0.262 \\
Error & 6 & 241.6 & 40.26 & & \\
\hline Total & 15 & 789.6 & & & \\
\hline
\end{tabular}

(f) HARDNESS

\begin{tabular}{|c|c|c|c|c|c|}
\hline Source & DF & Adj SS & Adj MS & $\begin{array}{r}\mathrm{F}- \\
\text { Value }\end{array}$ & $\begin{array}{r}\text { P- } \\
\text { Value }\end{array}$ \\
\hline $\bar{A}$ & 3 & 52.17 & 17.39 & 1.29 & 0.360 \\
\hline B & 3 & 34.76 & 11.585 & 0.86 & 0.511 \\
\hline $\mathrm{C}$ & 3 & 24.69 & 8.231 & 0.61 & 0.632 \\
\hline Error & 6 & 80.88 & 13.48 & & \\
\hline Total & 15 & 192.5 & & & \\
\hline
\end{tabular}

\subsection{VERIFICATION OF OPTIMUM CONDITION}

The essence of using Taguchi experimental design and ANOVA is to optimise the experimental process. Verification is done by carrying out new sets of experiments at the levels of the optimum 
parameters if the optimum conditions have not been experimented. Generally, the optimum condition may not be one that has already been tested. Thus you will need to run additional experiments to confirm the predicted performance. In this study, additional experiments were ran with the optimum condition as stated in section 3.3. A4B1C1 for UTS, A4B1C1 for Load, A4B3C1 for MOE, A4B1C2 for MOR, A4B3C3 for Impact and A4B3C1 for Hardness to obtain the experimental values. This is so because in Taguchi design the best combination may not correspond to any experimental run or combination of levels to predicted values as seen in this experiment.

To get the predicted values from our optimum combination, the use of equation is employed by combining the means of the parameters at different levels to arrive at a predicted optimum UTS, Load, MOE, MOR, Impact Strength and Hardness.

Since we are considering additive factors of the individual effect of parameter A, B, and C and their respective level of influence on the measured properties, six equations would be used.

$$
R_{P}=T_{R}+\left(A_{n}-T_{R}\right)+\left(B_{n}-T_{R}\right)+\left(C_{n}-T_{R}\right)
$$

Where:

RP is the predicted response or yield (UTS, Load, MOE, MOR, Impact Strength or Hardness)

$T_{\mathbf{R}}$ is the total mean value of $R$

$A_{\mathbf{n}}, B_{\mathbf{n}}$ and $C_{n}$ are the corresponding parameters at their respective experimental trials ' $n$ '.

For UTS, the optimum combination is A4B1C1

$$
\begin{aligned}
\mathrm{UTS}_{\mathbf{P}} & =\text { TUTS }+\left(\mathrm{A}_{4}-\mathrm{T}_{\text {UTS }}\right)+\left(\mathrm{B}_{1}-\mathrm{T}_{\mathrm{UTS}}\right)+\left(\mathrm{C}_{1}-\mathrm{T}_{\mathrm{UTS}}\right) \\
\mathrm{UTS}_{\mathrm{P}} & =8.884+(11.135-8.884)+(10.925-8.884)+(14.6825-8.884) \\
& =\mathbf{1 8 . 9 7 4 5}\left(\mathrm{T}_{\text {UTS }}=8.884, \mathrm{~A}_{4}=11.135, \mathrm{~B}_{1}=10.925, \mathrm{C}_{1}=14.6825\right)
\end{aligned}
$$

For LOAD, the optimum combination is $\mathrm{A} 4 \mathrm{~B} 1 \mathrm{C} 1$;

$$
\begin{aligned}
\text { LOADP } & =T_{\text {LOAD }}+\left(\mathrm{A}_{4}-\mathrm{T}_{\text {LOAD }}\right)+\left(\mathrm{B}_{1}-\mathrm{T}_{\text {LOAD }}\right)+\left(\mathrm{C}_{1}-\mathrm{T}_{\mathrm{LOAD}}\right) \\
& =\mathbf{1 1 6 1 . 8 7 4}\left(\mathrm{T}_{\mathrm{LOAD}}=578.438, \mathrm{~A}_{4}=714.584, \mathrm{~B}_{1}=683.3325, \mathrm{C}_{1}=920.8325\right)
\end{aligned}
$$

For MOE, the optimum combination is $\mathrm{A} 4 \mathrm{~B} 3 \mathrm{C} 1$;

$$
\begin{aligned}
& \text { MOEP }=\text { TMOE }+\left(\mathrm{A}_{4}-\mathrm{T}_{\text {MOE }}\right)+\left(\mathrm{B}_{3}-\mathrm{T}_{\text {MOE }}\right)+\left(\mathrm{C}_{1}-\mathrm{T}_{\text {MOE }}\right) \\
& =878.706\left(\mathrm{~T}_{\mathrm{MOE}}=583.272, \mathrm{~A}_{4}=830.0425, \mathrm{~B}_{3}=466.2375, \mathrm{C}_{1}=748.97\right)
\end{aligned}
$$

For MOR, the optimum combination is $\mathrm{A} 4 \mathrm{~B} 1 \mathrm{C} 2$;

$$
\begin{aligned}
M_{P} & =T_{M O R}+\left(A_{4}-T_{M O R}\right)+\left(B_{1}-T_{M O R}\right)+\left(C_{2}-T_{M O R}\right) \\
& =23.072\left(T_{M O R}=13.734, A_{4}=16.875, B_{1}=15.075, C_{2}=18.59\right)
\end{aligned}
$$


For Impact Strength (IMP), the optimum combination is A4B3C3;

$\mathrm{IMPP}=\mathrm{T}_{\text {IMP }}+\left(\mathrm{A}_{4}-\mathrm{T}_{\text {IMP }}\right)+\left(\mathrm{B}_{3}-\mathrm{T}_{\text {IMP }}\right)+\left(\mathrm{C}_{3}-\mathrm{T}_{\text {IMP }}\right)$

$=\mathbf{8 . 6 4 2 3}\left(\mathrm{T}_{\mathrm{IMP}}=4.06, \mathrm{~A}_{4}=5.39, \mathrm{~B}_{3}=5.1573, \mathrm{C}_{3}=6.215\right)$

For Hardness Value (HV), the optimum combination is A4B1C1

$\mathrm{HV}_{\mathbf{P}}=\mathrm{T}_{\mathbf{H V}}+\left(\mathrm{A}_{4}-\mathrm{T}_{\mathbf{H V}}\right)+\left(\mathrm{B}_{3}-\mathrm{T}_{\mathbf{H V}}\right)+\left(\mathrm{C}_{1}-\mathrm{T}_{\mathbf{H V}}\right)$

$=12.1145\left(T_{\mathrm{HV}}=7.904, \mathrm{~A}_{4}=9.1725, \mathrm{~B}_{3}=9.3175, \mathrm{C}_{1}=9.4325\right)$

\section{Verification Test}

\begin{tabular}{cccc} 
& Mean Combination & Optimum Combination & \\
\hline & & Experimental & Predicted \\
\hline Combination & A1B3C3 & & A4B1C1 \\
UTS & 7.04 & 7.1 & 18.97 \\
SNRA & 16.951 & 17.0252 & 25.5627 \\
\hline
\end{tabular}




\begin{tabular}{|c|c|c|c|}
\hline & $\begin{array}{c}\text { Improvement of } \\
\text { SNRA }=8.6117 \mathrm{~dB}\end{array}$ & & \\
\hline Combination & A4B3C2 & & A4B1C1 \\
\hline LOAD & 625 & 450 & 1161.87 \\
\hline \multirow[t]{2}{*}{ SNRA } & 55.92 & 53.0627 & 61.3018 \\
\hline & $\begin{array}{l}\text { Improvement of } \\
\text { SNRA }=5.3818 \mathrm{~dB}\end{array}$ & & \\
\hline Combination & A4B4C1 & & A4B3C1 \\
\hline MOE & 398.01 & 493 & 878.71 \\
\hline \multirow[t]{2}{*}{ SNRA } & 52 & 53.8616 & 58.86 \\
\hline & $\begin{array}{l}\text { Improvement of } \\
\text { SNRA }=6.86 \mathrm{~dB}\end{array}$ & & \\
\hline Combination & A2B2C1 & & A4B1C2 \\
\hline MOR & 11.4 & 27.29 & 23.07 \\
\hline \multirow[t]{2}{*}{ SNRA } & 21.14 & 28.7192 & 27.26 \\
\hline & $\begin{array}{l}\text { Improvement of } \\
\text { SNRA }=6.12 \mathrm{~dB}\end{array}$ & & \\
\hline Combination & A3B3C1 & & A4B3C3 \\
\hline IMP & 3.07 & 8.2 & 8.6 \\
\hline \multirow[t]{2}{*}{ SNRA } & 9.74 & 18.276 & 18.7325 \\
\hline & $\begin{array}{c}\text { Improvement of } \\
\text { SNRA }=8.9925 \mathrm{~dB}\end{array}$ & & \\
\hline Combination & A2B4C3 & & A4B3C1 \\
\hline HV & 8.07 & 31.13 & 12.11 \\
\hline SNRA & 18.14 & 29.8632 & 21.6659 \\
\hline
\end{tabular}

\subsection{CONCLUSION}

The mechanical properties of snail shell /chicken feather polyester composite have been studied using Taguchi and ANOVA method. The properties studied were ultimate tensile strength (UTS), load carrying capacity (Load), modulus of elasticity (MOE) and rupture (MOR), impact strength (IMP) and hardness. These properties were studied under the variation of snail shell particulates and chicken feather fibre embedded in the matrix of polyester resin. The variations of the mechanical properties as these parameters changes were recorded. The table of ANOVA shows the respective effect of snail shell particulate and chicken feather fibre on the mechanical properties of the composite at 95\% confidence level. CFF has 69.46\%, 66.64\%, 37.88\% and $42.93 \%$ significant effect on UTS, Load, MOR and Impact respectively, while SSF and SPSS have 40.69\% and $46.74 \%$ significant effect on MOE and Hardness value respectively. With these, depending on properties of interest one will watch the variation of CFF closely if UTS, Load, MOR and Impact strength are the properties of interest, SSF if MOE is the properties of interest and SPSS if Hardness is the properties of interest. An improvement of the SN ratio was observation when verification test conducted for UTS, MOE, MOR, IMP and HV from the mean values to the experimental values. 


\section{REFERENCES}

Asafa T.B.; Durowoju, M.O.; Oyewole, A.A.; Solomon, S.O.; Adegoke, R.M. and O. J. Aremu. Potentials of Snailshell as a Reinforcement for Discarded Aluminum Based Materials. International Journal of Advanced Science and Technology Vol.84 (2015), pp.1-8 http://dx.doi.org/10.14257/ijast.2015.84.01. ISSN: 2005-

Andreia Leite dos Santos Alves, Lucio Fabio Cassiano Nascimento, \& Joa ̃o carlos Miguez Suarez. (2005). Influence of Weathering and Gamma Irradiation on the Mechanical and Ballistic Behaviour of UHMWPE Composite Armor. Polymer Testing, 24(05), 104-113.

Bienia, J.; Walczak, M.; Surowska, B and J. Sobczaka, "Microstructure and corrosion behaviour of aluminum fly ash composites", Journal of Optoelectronics and Advanced Materials, vol. 5, no. 2, (2003), pp. 493-502.

Bless. J, Jurick.D.L, Timothy.S.P and Reynolds.M.A(2015): Shockwave and High Strain Rate Phenomena in Materials, Eds.(Mark A,Meyers et al.) pp 1051-1058.

Kelly A.; The Nature of Composite Materials, scientific American Magazine 217, (B), (1967): p. 161.

Ku, H.; Wang, H.; Pattarachaiyakoop, N, and M. Trada, "A review on the tensile properties of natural fiber reinforced polymer composites," Composites Part B: Engineering, vol. 42, no. 4, pp. 856-873, 2011.

Lucas A.M. and Stettenheim, P.R. Avian Anatomy: Integument, United States Agricultural Research Service, Washington (1972).

Madueke, C.I.; Bolasodun, B.; Umunakwe; Reginald, U. and Nwonah, JN. (2014). Comparison of the Mechanical Properties of Charcoal Unsaturated Polyester Matrix Composite and Snail shell Unsaturated Polyester Matrix Composite. International Journal of Scientific \& Engineering Research, Volume 5, Issue 11, November-2014, 208 ISSN 2229-5518 IJSER (C) 2014 http://www.ijser.org

Patricio, T.; Quijad, R.L.; Yazdani-Pedram, J.L. and Arias, M. "Eggshell a new biofiller for polypropylene composites”, Mater. Lett., vol. 61, no. 22, (2007), pp. 4347-4350.

Prasad, S.P. and Krishna, R.A "Production and Mechanical Properties of A356.2 /RHA Composites”, International Journal of Adv. Sci. Technol., vol. 33, (2011), pp. 5158.

Shalwan A., and Yousif BF. (2013). Mechanical and Tribological Behaviour of Polymeric Composites Based on Natural Fibers. J Mater Desi 48:14-24.

Shalwan, A. and Yousif, B.F. "In state of art: mechanical and tribological behaviour of polymeric composites based on natural fibres," Materials \& Design, vol. 48, pp. 14-24, 2013.

Subramani T.; Krishnan, S.; Ganesan S.K and Nagarajan G. Investigation of Mechanical Properties in Polyester and Phenylester Composites Reinforced With Chicken Feather Fiber. Int. Journal of Engineering Research and Applications www.ijera.com ISSN : 2248-9622, Vol. 4, Issue 12( Part 4), December 2014, pp.93-104.

Syed, TZ. and Vaishali G.G. (2014). Experimental Investigation of Snail Shell Ash (SSA) as Partial Repalacement of Ordinary Portland Cement in Concrete. An International Journal of Engineering Research \& Technology (IJERT). ISSN:22780181. Vol. 3 Issue 10.

Ticoalu, T. Aravinthan, and F. Cardona, “A review of current development in natural 
fiber composites for structural and infrastructure applications," in Proceedings of the Southern Region Engineering Conference (SREC '10), pp. 113-117, Toowoomba, Australia, November 2010.)

Zhan M. and Wool, R.P. Bio-Based Dielectric Materials for Printed Circuit Boards," in The 12th Annual Green Chemistry and Engineering Conference, Washington, D.C. (2008)

Zhan M. and Wool, R.P. Evaluation of Electrical and Mechanical Properties of Composites Made from Epoxy and Feather Fibers, in The 14th Annual Green Chemistry and Engineering Conference, Washington, DC (2010). 